\title{
Technology for Enhancing Chest Auscultation in Clinical Simulation
}

\author{
Jeffrey J Ward MEd RRT and Bryan A Wattier RRT
}

\author{
Introduction \\ Audio and Web-Based Chest Auscultation Resources \\ Auscultation Task Trainers \\ Chest Auscultation Full-Function Manikins \\ Recording Stethoscopes and Digital Software \\ Auscultation Sound Generating Devices \\ Discussion \\ Summary
}

\begin{abstract}
The ability to use an acoustic stethoscope to detect lung and/or heart sounds, and then to then communicate one's interpretation of those sounds is an essential skill for many medical professionals. Interpretation of lung and heart sounds, in the context of history and other examination findings, often aids the differential diagnosis. Bedside assessment of changing auscultation findings may also guide treatment. Learning lung and heart auscultation skills typically involves listening to pre-recorded normal and adventitious sounds, often followed by laboratory instruction to guide stethoscope placement, and finally correlating the sounds with the associated pathophysiology and pathology. Recently, medical simulation has become an important tool for teaching prior to clinical practice, and for evaluating bedside auscultation skills. When simulating cardiovascular or pulmonary problems, high-quality lung and heart sounds should be able to accurately corroborate other findings such as vital signs, arterial blood gas values, or imaging. Digital audio technology, the Internet, and high-fidelity simulators have increased opportunities for educators and learners. We review the application of these technologies and describe options for reproducing lung and heart sounds, as well as their advantages and potential limitations. Key words: clinical simulation; auscultation; lung sounds; heart sounds. [Respir Care 2011;56(6):834-845. (c) 2011 Daedalus Enterprises]
\end{abstract}

\section{Introduction}

Over the past 15 years, medical simulation has undergone rapid growth as an important technique to provide

The authors are affiliated with the Respiratory Care Program, Mayo College of Medicine, University of Minnesota, Rochester, Minnesota. Mr Ward is also affiliated with the Mayo Clinic Multidisciplinary Simulation Center.

The authors have disclosed no conflicts of interest.

Supplementary material related to this paper is available at http:// www.rcjournal.com.

Correspondence: Jeffrey J Ward MEd RRT, Respiratory Care Program, Mayo College of Medicine, University of Minnesota, 200 1st Street SW, Siebens 10-12D, Rochester MN 55905. E-mail: ward.jeffrey@mayo.edu. education as well as clinical evaluation..$^{1,2}$ Acceptance may be based on the proliferation of high-fidelity manikin technology. However, it also relates to greater appreciation for the value of this tool to facilitate experiential education. Simulation has been cited as a strategy to improve safety (learner and patient), and to impact quality and accountability in medical practice. ${ }^{3-8}$ There is also growing documentation of research-based evidence for medical simulation. ${ }^{9}$

Use of an acoustic stethoscope to hear, interpret, and communicate findings of lung and/or heart sounds is an

DOI: $10.4187 /$ respcare 01072 
important skill for medical professionals involved in cardiopulmonary care. Accurate reproduction of realistic lung and heart sounds can affect the quality and outcome of learning and/or evaluation in simulation events. The purpose of this paper is to review current chest auscultation technology and discuss the potential for improving its application when used prior to or during medical simulation. Digital audio files now allow manufacturers to upload highfidelity mechanical manikins with a selection of heart and lung sounds; typically, they are synchronized with the manikin's pulmonary and cardiovascular events. In addition, educators can upload playback devices with pre-recorded MP3 audio files for use with standardized patients. A standardized patient is an individual who portrays a patient and allows learners to incorporate realistic human interaction, including communication and physical examination, in a simulated clinical setting. Standardized patients can communicate important history and symptoms during a simulation. During physical examination they can rarely convey sounds of their attributed pathology, as they typically have few or no abnormal physical findings. ${ }^{10}$ This paper will review: media for pre-clinical auscultation training; task-trainers and manikins; electronic stethoscopes and software for recording lung and heart sounds; and soundgenerating devices and stethoscopes for playback of lung and heart sound files.

The process of chest auscultation requires human interaction skills and supports physical contact with patients. For the learner it requires development in understanding the physics of acoustics, the reasons for changes in normal breath sounds, and the pathology of adventitious sounds. A blend of cognitive abilities for interpretation and a framework of accepted terminology is required for effective communication. ${ }^{11}$ A discussion of the efficacy of chest auscultation, differences of terminology usage, and the comparative value of acoustic stethoscope auscultation to either imaging or sonographic technology in current medical practice is beyond the scope of this paper but frequently appears in the medical literature. ${ }^{12-14}$

\section{Audio and Web-Based Chest Auscultation Resources}

Prior to learners becoming engaged with simulation or real patients, it is important that they be prepared in the classroom or laboratory. Pre-recorded lung sounds have been used to teach sound recognition for many years. In the 1970s and 1980s, cassette tapes were used for preclinical teaching, and often these were accompanied with written text or photograph-slide presentations; later, video tapes became available. ${ }^{15,16}$ In the 1990s, digital sound files became available, in MPEG-1 Audio Layer 3 (MP3) and Waveform Audio File Format (WAV or WAVE) files or proprietary variants. There are currently a number of CD-ROM training presentations that provide basic inter-

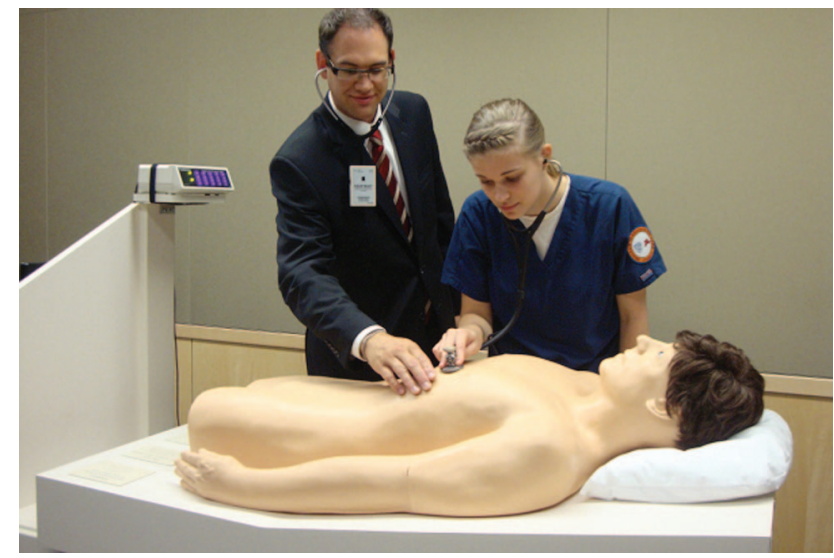

Fig. 1. Harvey cardiology patient simulator. The learner is placing the master stethoscope on manikin chest, which signals, via infrared signal to the wireless transmitter at left, transmission to the stethoscope worn by the instructor.

pretation of lung and heart sounds and case-based examples. Often a hybrid format provides text, diagrams, or sonograms with some interactive features. In addition, there are a number of Internet web sites (commercial and noncommercial) that offer teaching files. Success of these methods, often facilitated in small groups, has been reported. ${ }^{17-20}$ An experienced mentor can model auscultation technique and guide the novice in the interpretation of chest sounds. Recordings used in training do not account for variations in body habitus or pathology. (Refer to the supplementary resources at http://www.rcjournal.com for a listing of CD-ROMs and Web sites).

\section{Auscultation Task Trainers}

There are several commercially available chest auscultation task trainer manikins. These devices allow learners to go beyond passive listening to either audio CDs or limited interaction using computer software. In this highfidelity technology, learners apply their stethoscopes in generally accepted positions for auscultation on plastic encased torsos. Correlation of lobar sounds and external chest landmarks reinforce correct placement. The earliest simulator of this type was Harvey (Laerdal Medical, Wappingers Falls, New York), developed by Dr Michael Gordon in 1968. It is a full-size torso fixed in the supine position on an exam-table-like console (Fig. 1). As a primarily cardiovascular exam trainer, it is able to simulate arterial blood pressure, jugular venous pulse waveforms, precordial pulses, as well as cardiac and respiratory sounds. Specific sounds (eg, wheezing or crackles) cannot be specifically selected for playback. The device can also demonstrate the effect of respiration on pulse and simulate signs of a spectrum of cardiac diseases. A speaker in the second generation of Harvey allows operator voice to con- 


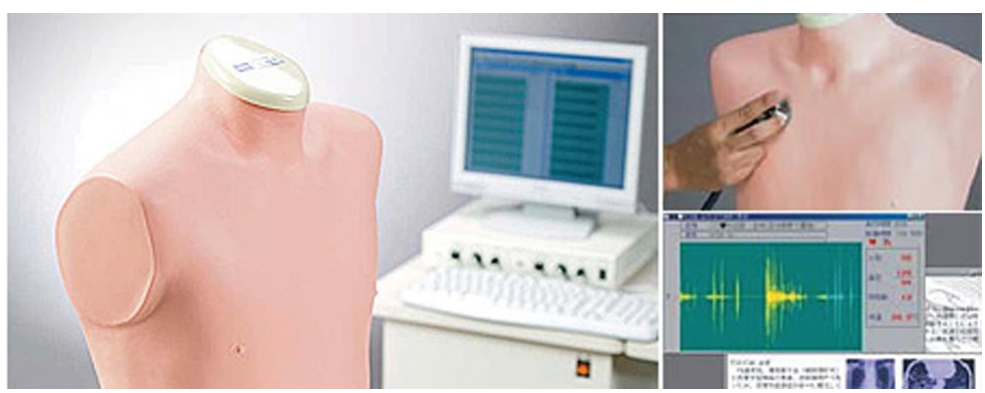

Fig. 2. Lung Sound Auscultation Skills and Training (LSAT) manikin and accompanying computer and auxiliary speakers. (Courtesy of Kyoto Kagaku.)

vey speech, to better allow for use in simulation scenarios. In faculty-led small-group tutorials, a specific pathology can be set by actuating controls on the console. A companion multimedia computer presentation of 30 cardiovascular conditions (UMedic, Laerdal Medical, Wappingers Falls, New York), is available to complement use of Harvey for tutorial or self-instruction. Lung and heart sounds are transmitted from 6 and 9 zones, respectively. Sounds are conveyed by speaker to a primary stethoscope, and wirelessly to multiple other stethoscopes via infrared technology. When the master stethoscope is placed on specific zones on the chest, magnetic signaling elicits preprogrammed sound playback. ${ }^{21}$ There have been a number of studies validating the educational efficacy of this simulation technology for a variety of physician, nursing, and allied health clinicians. ${ }^{22,23}$

In the late 1990s, success of the auscultation task trainer concept prompted development of a similar cardiology patient simulator in Japan, the Cardiology Patient Simulator System K (Kyoto Kagaku, Kyoto, Japan), which provides similar physical exam features, including cardiovascular pulsations and auscultation. The manikin torso is more compact than Harvey, because the computer and mechanical control system are separated from the exam table. Both torsos are fixed in the supine position. The manufacturer supports simulation and independent selfstudy education by providing a range of cardiac disease scenario cases as well as electrocardiogram tutorials using an accompanying computer and monitor. Heart sounds are conveyed through the manikin's chest wall via internal speakers, and may also be played through external loudspeakers. ${ }^{24}$ Kyoto Kagaku also produces a K-Plus simulator that resembles System K but adds the function of being able to also select simulated lung sounds.

Currently there are 4 commercial upright torso auscultation task trainers. These are simplified devices, as they either do not have complex mechanical systems to simulate vascular and/or heart pulsations, or they are simplified compared to the aforementioned devices. Two Japanese-made models include the Sakamoto Auscultation Simulator (Sakamoto Model, Osaka, Japan) and the Lung Sound Auscultation
Trainer (LSAT) manikin (Kyoto Kagaku, Kyoto, Japan). Both generate lung sounds and cardiac sounds with speakers inside the torso or external loudspeakers (Fig. 2). Accompanying computer systems are required to control the selection of cardiac and lung sounds. Unlike with the fixed-supine-position trainers, learners can access the dorsal/posterior lung zones. $^{25}$ In the United States, Cardionics (Webster, Texas) produces a similar upright torso trainer called the Student Auscultation Manikin (SAM) (Fig. 3). It can reproduce lung, heart, and bowel sounds, as well as carotid pulsations. The task trainer can be used for individual training with clinical acoustic stethoscopes or demonstrate sound for groups, using wireless infrared SimulScope, a technology similar to that of Harvey. The same company also produces PneumoSim, which incorporates a console that generates simulated and real breath sounds to be heard; an accompanying laptop computer provides graphic sound display. Another United States manufacturer, Nasco (Fort Atkinson, Wisconsin), produces a similar adult auscultation trainer, and an infant version. In contrast to the previously mentioned trainers, lung and heart sounds are not generated from speakers within the torso, but through a special stethoscope (Smartscope). Specific lung and heart sounds are programmed with a wireless remote control. As the learner's stethoscope is placed at specific areas of the torso, pre-specified sound files are activated and then played through the stethoscope's transceiver. A dual headset stethoscope or remote speaker can also convey the sounds (Fig. 4). The infant trainer employs a full-body manikin with similar (but not interchangeable) controller and Smartscope. A limited range of lung and heart sounds is offered, but 4 bowel sounds may be selected. Table 1 summarizes capabilities of the aforementioned chest auscultation task trainers.

\section{Chest Auscultation Full-Function Manikins}

Early full-body manikins required limited functionality to accomplish training objectives. The first production medicaloriented manikin in the United States was made in 1910, by the Chase Doll Company (Pawtucket, Rhode Island). The Chase Hospital Doll ("Mrs Chase") was used to teach bedside nursing skills. In 1914 she was upgraded with an injec- 


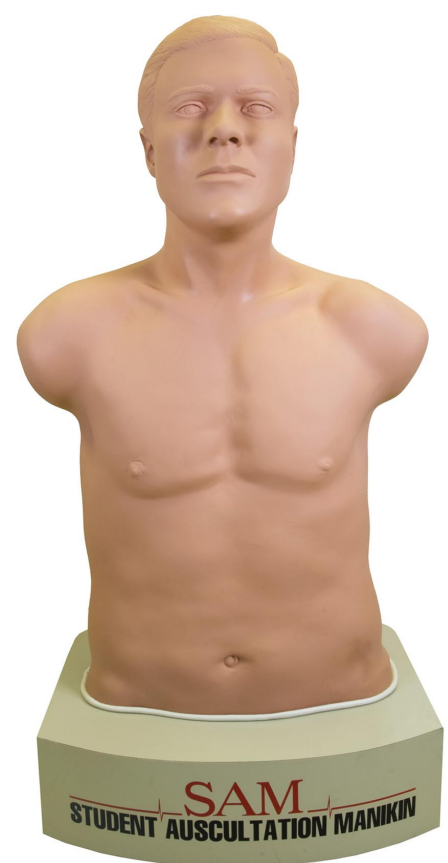

Fig. 3. Student Auscultation Manikin (SAM). (Courtesy of Cardionics.)

tion site and an internal reservoir that permitted urethral, vaginal, and rectal treatments. In the 1940s a male version was developed to allow training of United States Army corpsmen. ${ }^{26}$ Following initial acceptance, in the mid-1960s, of mouth-to-mouth ventilation and, later, chest-compression for cardiopulmonary resuscitation, Resusci-Anne (Laerdal Medical, Wappingers Falls, New York) was developed. ${ }^{27}$ More comprehensive training for the operating room and control function from an analog computer led Drs Stephen Abrahamson and Judson Denson to develop Sim One in the late 1960s. Although it was never commercially produced, it led Dr David Gaba to develop the Comprehensive Anesthesia Simulation Environment system and the accompanying Anesthesia Crisis Resource Management curriculum in the mid-1980s, in a hospital affiliated with Stanford Medical School. A commercial version of that manikin was equipped with palpable pulses and had spontaneous breathing with heart and lung sounds; it had a limited period of commercial production. Similar clinical needs prompted Drs Michael Good and JS Gravenstein to develop the Gainesville Anesthesia Simulator with software to enable predefined sequences of physiological functions that could change based on the learner's actions. Commercial adaptation later occurred in the Human Patient Simulator and the Emergency Care Simulator (Medical Education Technologies, Sarasota, Florida). In the mid1990s, Laerdal Medical developed a series of manikins with improved upper-airway anatomy (AirMan) and subsequently produced a full-body high-fidelity manikin (SimMan). AirMan can reproduce only normal vesicular sounds; when the

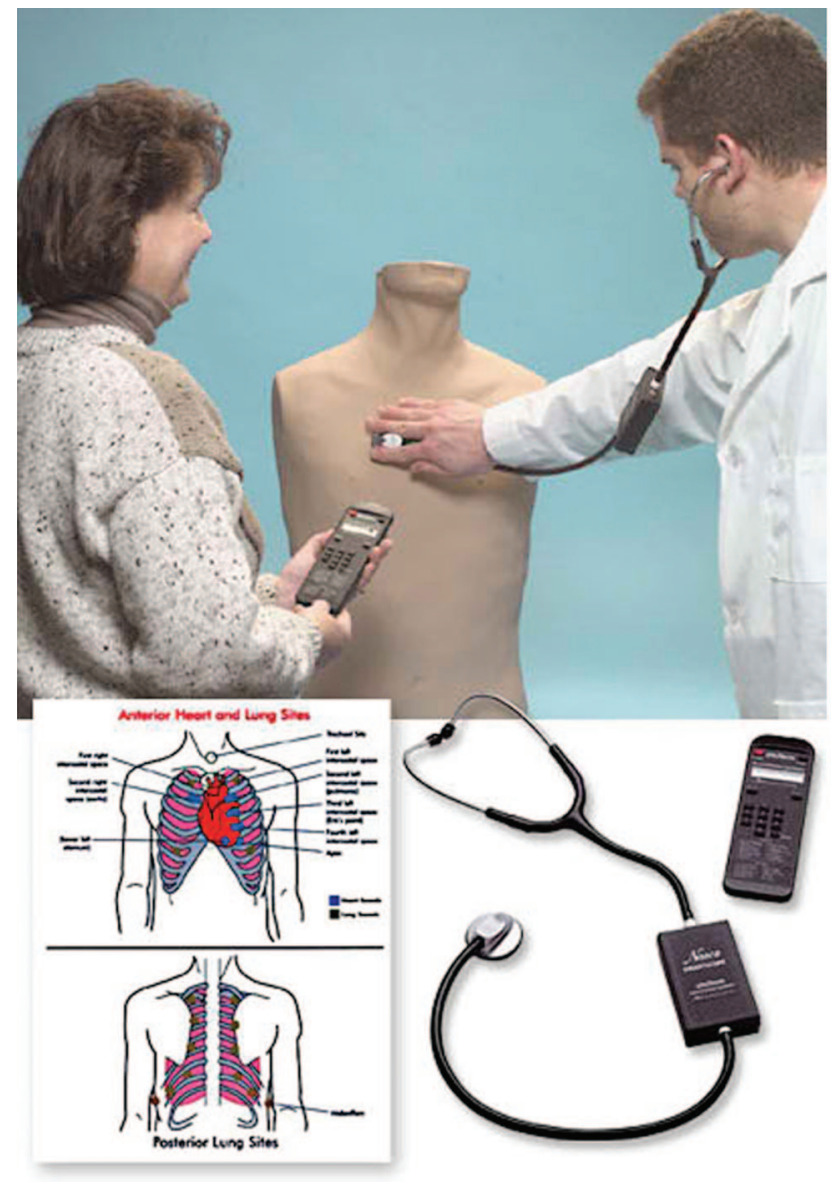

Fig. 4. Life/Form Auscultation Trainer and Smartscope. With the remote control the instructor selects heart and lung sounds that are transmitted to a transceiver in the learner's stethoscope. (Courtesy of Nasco.)

pneumothorax control is selected, lung sounds to speakers and expansion to that hemithorax can both be reduced. SimMan can simulate both normal heart and lung sounds, synchronized with the manikin's physical (mechanical) actions, and crackles and wheezes. ${ }^{28}$

Most commercial manufacturers of full-body high-fidelity manikins provide pre-recorded heart and lung sounds from digital audio files in the software. The sound files are "read-only" (ie, cannot be changed or replaced with other sounds). As with task trainers, the lung sounds are synchronized with respiratory rate, and some can be controlled for either bilateral or unilateral application. A variety of adventitious sounds, which emanate from lungs/airway, pleural surfaces, and/or voice sounds are available. With the Laerdal Medical manikins the speech function can be altered to simulate voice sounds (eg, stridor). Most operating software allows volume adjustment. On most manikins, when a pneumothorax is selected in the control software, the breath sounds are automatically deleted from the affected hemithorax. The Laerdal Medical SimMan 3G 


\section{Technology for Enhancing Chest Auscultation in Clinical Simulation}

Table 1. Auscultation Task Trainers

\begin{tabular}{lccc}
\hline \hline \multicolumn{1}{c}{ Model and Company } & \multicolumn{1}{c}{ Technology } & Heart Sounds & Lung Sounds \\
\hline Harvey & $42 \mathrm{~kg}$. Supine position. Magnetically & 9 auscultation areas. 12 impulses. & 6 breath-sound transmission areas. \\
Laerdal Medical & actuated. Infrared wireless audio & Sounds and pulses simulate & Specific breath sounds cannot be \\
& control transmitted to special & selected pathologies. & selected for playback. Lung \\
& stethoscope. Interactive computer & & cardiovalate specific \\
& link to UMedic software. 30 cardiac & & cardisorders.
\end{tabular}

K-Plus

Kyoto Kagaku

Lung Sound Auscultation

Trainer

Kyoto Kagaku

Sakamoto Auscultation

Simulator

Sakamoto Model

Student Auscultation

Manikin

Cardionics

Life/Form Auscultation

Trainer (adult)

Nasco

Life/Form Auscultation

Trainer (infant)

Nasco
$10 \mathrm{~kg}$. Supine position. 7 internal speakers. 4-channel vital signs system. Uses standard acoustic stethoscope or external speakers. Software has 88 cardiac case scenarios: 36 total patient simulations and 52 case scenarios of arrhythmia with electrocardiogram simulation.

$10 \mathrm{~kg}$. Upright torso with rotary base. Computer interface with sound graphic display. 15 speakers inside the torso ( 7 anterior, 8 posterior). 34 case scenarios, with 2 versions (with and without heart sounds). Uses standard acoustic stethoscope and/or external speakers.

$14 \mathrm{~kg}$. Upright torso. 7 internal speakers. Adjustable volume. Accompanying computer controls 20 cardiac and 12 breath-sound case scenarios.

$10 \mathrm{~kg}$. Portable. Upright torso. Computer selects heart and lung sounds. Uses acoustic stethoscope. Breath sounds at 8 , heart sounds at 4 , and bowel sounds at 2 anatomical locations. Palpable carotid pulse and thrills for heart murmurs. Options: Infrared SimulScope and phonocardiographic display. On-line training Web site.

$12.3 \mathrm{~kg}$. Lung: 5 anterior, 10 posterior, and 2 midaxillary locations. Heart: 6 anterior sites. Remote controller selects heart and lung sounds. Smartscope plays sounds through in-stethoscope transceiver. Placement of stethoscope on chest activates transponder playback of audio files. Dual headsets and remote speaker playback options.

$8.6 \mathrm{~kg} .14 \mathrm{~kg}$ with speaker. Sites for sound activation: 1 heart, 1 bowel, 2 anterior lung, and 2 posterior lung. Remote controller selects heart and lung sounds. Placement of Smartscope on chest activates playback of audio files. Dual headsets and remote speaker playback options.
Normal jugular venous waves, arterial pulses, cardiac impulses, and heart sounds, including S2 splitting in the pulmonic area, and $\mathrm{S} 3$ and $\mathrm{S} 4$ gallop in the mitral area.

Same as K-Plus.

Normal, splitting and increased S2, S3, S4; tricuspid, pulmonary, mitral, and aortic valve insufficiency; mitral stenosis; atrial or ventricular septal defect; mitral escape; innocent murmurs.

Normal, physiologic, and paradoxical splitting of S2, S3, S4; mitral valve stenosis, prolapse, and regurgitation; aortic valve stenosis regurgitation; pulmonary stenosis; hypertrophic cardiomyopathy; acute pericarditis. Palpation of systolic thrills.

Aortic regurgitation, atrial septal defect, ventricular septal defect, holosystolic and midsystolic murmurs, mitral stenosis, patent ductus arteriosus, pulmonary, stenosis, S3, S4, and systolic click.

Normal newborn and 1-year-old heart. Aortic stenosis, atrial septal defect, ventricular septal defect, S2 splitting, mitral regurgitation, venous hum, Still heart murmur.
Normal lung sounds, coarse and fine crackles, wheezes, rhonchi, squawk, stridor, pleural friction rub, vocal fremitus.

Breath sounds can be selected for specific playback or in case scenarios. Normal sounds, coarse and fine crackles, wheezes, rhonchi, rhonchi + wheeze, squawk, stridor, pleural friction rub, pneumomediastinum, palpable vocal fremitus.

Fine and coarse crackles, rhonchi, wheezes, wheeze + crackles, shallow tachypnea, hyperventilation. Adjustable respiratory rate.

Normal lung sounds. Normal voice sounds (bronchophony, pectoriloquy and egophony). Fine, medium, and coarse crackles, wheeze, rhonchus, stridor, pleural rub, COPD, emphysema, lobar pneumonia, and chronic bronchitis. Adjustable inspiratory/expiratory ratio and placement of lung sound in breath cycle. Sounds can be limited to one hemithorax.

Normal vesicular adult and infant, bronchovesicular, bronchial, cavernous, coarse and fine crackles, wheezes, egophony, pleural friction rub, pectoriloquy, and stridor.

Normal lung sounds, wheezing, crackles, rhonchi, stridor of newborn and 9-month old. 


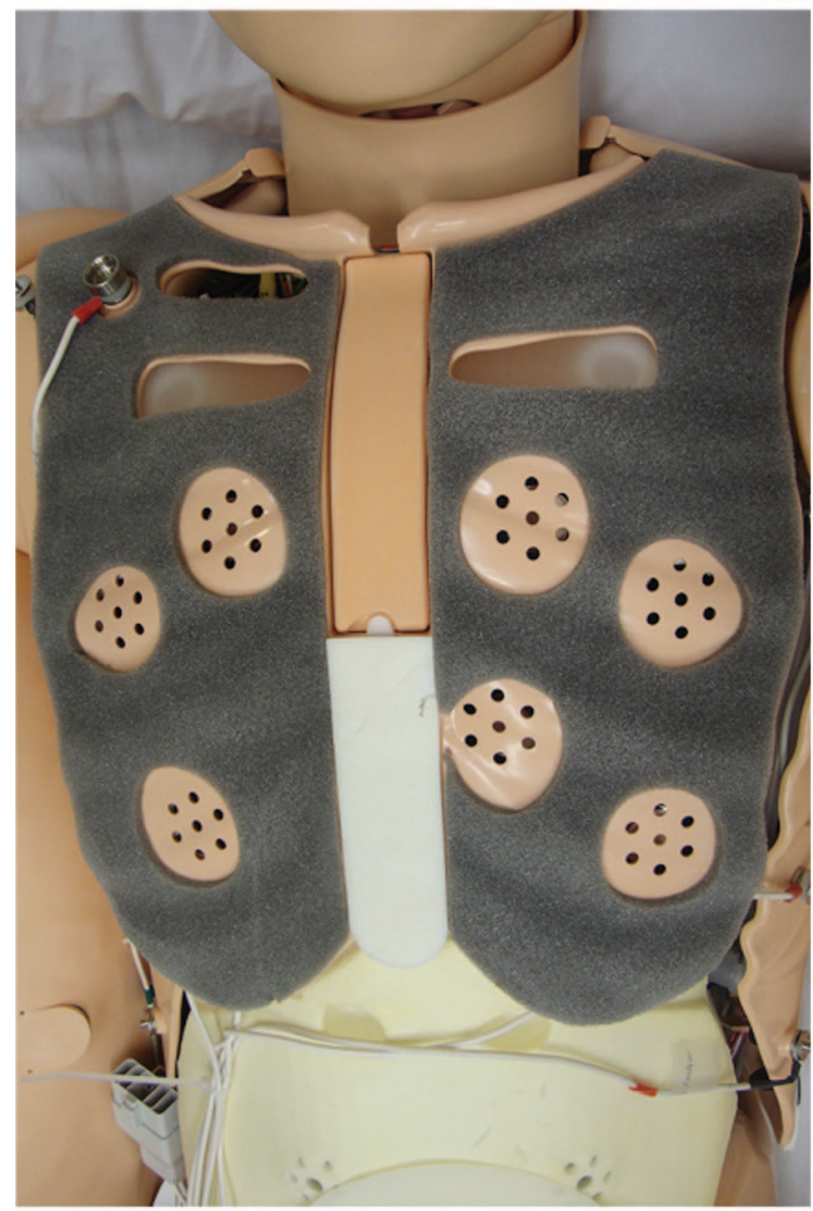

Fig. 5. Left: Photo of speakers within 3G chest plates. Right: Diagrams of speakers in SimMan 3G manikin. (Courtesy of Laerdal Medical.)

manikin has multiple speakers (Fig. 5), which allows independent playback of lung and heart sounds in the upper, lower, anterior, and/or posterior chest surfaces.

The quality of lung and heart sound reproduction in many high-fidelity manikins has limitations. Speakers have limited dynamic range and may not faithfully reproduce lung or heart sounds. Limited number and location of speakers make stethoscope placement critical. In addition, the plastic skin acts as insulation that interferes with sound transmission. Mechanical noises produced by the manikin's internal hardware can overlap the lung and heart sounds and distract learners. This is especially noticeable with wireless manikins that use internal compressors to drive their mechanical functions.

Cardiovascular sound files are also commonly provided, and are of varying levels of sophistication with regard to


concomitant visual pulsation, palpation, and electrocardiogram findings that would parallel normal physiology or pathology. Table 2 summarizes the capabilities of currently available high-fidelity manikins.

\section{Recording Stethoscopes and Digital Software}

Since the 1950s, physiologists and clinicians have been interested in recording lung and heart sounds to better understand both normal and pathologic acoustic relationships. ${ }^{29}$ Advances in cardiology allowed visual/sound images in the form of the phonocardiogram. However, its 


\section{Technology for Enhancing Chest Auscultation in Clinical Simulation}

Table 2. High-Fidelity Manikins

\begin{tabular}{|c|c|c|c|}
\hline Model and Company & Technology & Heart Sounds & Lung Sounds \\
\hline $\begin{array}{l}\text { S3000 Hal and S2000 Susie } \\
\text { Gaumard Scientific }\end{array}$ & $\begin{array}{l}\text { Internal speakers. Anterior and } \\
\text { posterior lung sounds ( } 8 \text { sites). } \\
\text { Wireless }\end{array}$ & $\begin{array}{l}\text { Pulse strengths and Korotkoff sounds } \\
\text { vary with blood pressure. } \\
\text { Pulse is synchronized with } \\
\text { electrocardiogram. Normal heart }\end{array}$ & $\begin{array}{l}\text { Normal, none/absent (unilateral or } \\
\text { bilateral), wheezing, inspiratory } \\
\text { squeaks, crackles. }\end{array}$ \\
\hline
\end{tabular}

electrocardiogram. Normal heart

sound (absent and distant). Systolic

murmur, S3, S4, physiologic S2

split, aortic regurgitation, aortic

stenosis, mitral valve prolapse,

mitral stenosis, and mitral

regurgitation.

Pediatric Hal S3005 (5-year-old) Internal speakers: 2 anterior and S3004 (1-year-old)

Gaumard Scientific

lung, 1 anterior heart

S3009 Premi and S3010 Newborn Gaumard Scientific

Internal speakers: 2 anterior lung, 1 anterior heart

\section{SimMan \\ Laerdal Medical}

SimMan 3G

Laerdal Medical

SimBaby

Laerdal Medical

Human Patient Simulator and

Emergency Care Simulator

Medical Education Technologies
Internal speakers: 2 upper 1 heart

Lungs: 3 right anterior speakers (upper, middle, lower), 1 lateral and 2 posterior (upper and basal) left anterior speakers (upper and lower), 1 lateral and 2 posterior (upper and basal) speakers. Heart: 4 speakers: aortic, pulmonary, tricuspid, and mitral areas. Internal compressor can be turned off for $30 \mathrm{~s}$ for "auscultation focus." Wireless

Internal speakers: 3 anterior lung speakers (left and right upper). 1 heart speaker.

Internal speakers: anterior and lateral lung. anterior and 2 lateral lung,
Normal heart sounds, rates, and intensities; Korotkoff sounds, pulse strength varies with blood pressure, and pulse is synchronized with electrocardiogram. Bilateral carotid, brachial, and radial pulses operate continuously.

Normal heart sounds, atrial or ventricular septal defect. Umbilical, brachial, and fontanel pulsations.

Bilateral femoral, left radial, and brachial pulses.

Normal, aortic stenosis, early and holosystolic systolic murmur, diastolic murmur, continuous murmur, Austin Flint murmur, Stills murmur, gallop, pulmonary stenosis, ventricular or atrial septal defect, pericardial friction rub, mitral valve prolapse.

Heart sounds: normal, systolic murmur, holosystolic murmur, diastolic murmur, continuous murmur, and gallop.

Normal, S3, S4, S3+4; early, mid, late, and pan-systolic murmur; late diastolic murmur.
Normal, bronchial, wheezing crackles, pleural friction rub, voice sounds inspiratory, expiratory, and biphasic stridor.

Normal, absent, differential right vs left, bronchial, wheezing crackles, pleural friction rub, voice sounds, soft and strong grunting.

Normal (differential right vs left), bronchial, wheezing, crackles, pleural friction rub, stridor, grunting.

Normal (differential right vs left sound selection and some lobar differentiation), bronchial pneumonia, wheezing, coarse and fine crackles, rhonchi, gurgling rhonchi, stridor, pleural friction rub, upper or basal crackles, lower-lobe pneumonia, COPD exacerbation.

Differential: Right vs left selection of bronchial, wheezing, fine crackles, rhonchi, pleural friction rub, stridor, grunting.

Normal. Bilateral adjustment of crackles, rales, wheezes, muffled breath sounds. Lung sounds can be deleted unilaterally. clinical usefulness is significantly enhanced when combined with an echocardiogram. Early audio recording of pulmonary sounds was with phonocardiograph microphones applied to the chest. Later enhancements of microphone technology and sound acoustic imaging have been advanced by frequency spectral analysis with fast Fourier transformation and time-expanded waveform analysis. ${ }^{30,31}$
There have even been efforts to standardize this technology. ${ }^{32,33}$ At present there is limited clinical application of audio-computer graphic recordings to quantify lung sounds; a greater value for this technology appears to be in research and teaching. ${ }^{34,35}$

For some time, medical educators have had interest in collecting lung and/or heart sounds for teaching classroom- 


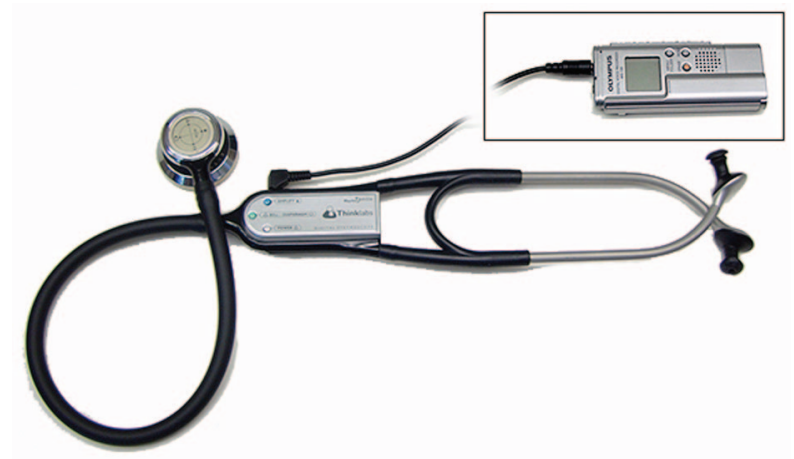

Fig. 6. Thinklabs Electronic Stethoscope ds32a, and connection to digital recording device.

based case studies; this now also applies to clinical simulation. The process has become more user-based with digital audio technology. Currently there are several electronic stethoscopes with added functionality to record heart and/or lung sounds as digital files. Most have some capability to amplify sounds as well as to reduce ambient room noise. Sound analysis software is available to allow visual display of the acoustic waveforms. Portable computers can be adapted for recording, including hand-held devices such as the iPod Touch or iPhone (Apple, Cupertino, California). Figure 6 shows the ds32a (Thinklabs, Centennial, Colorado) recording stethoscope connected to a digital recording device. Cardionics also produces the CardioSim Digital Breath Sound Simulator. It functions similarly to the previously mentioned CD playback device, and allows playback and some manipulation of 26 pre-recorded breath sounds. However, it also allows digital recording of sounds from live patients and can graphically display the recordings on a computer monitor. Table 3 list currently available recording stethoscopes.

\section{Auscultation Sound Generating Devices}

The need to provide high-quality and realistic heart and lung sounds for simulation-based training or examination with standardized patients, has fostered the development of auscultation playback devices. During simulated patient encounters, standardized patients can reveal information on history and symptoms. With appropriate makeup, and the use of sham vital sign monitors, various pathologies can be mimicked and their manifestations altered as scenarios unfold. However, standardized patients rarely can provide the pathological heart or lung sounds of their attributed disorder.

Currently there is one commercially available stethoscope that has been modified to receive wirelessly transmitted digital audio files from a remote source transmitter. The Ventriloscope (Lecat Ventriloscope, Akron, Ohio) is based on the Nordic (Oslo, Norway) RF24Z1 semiconductor $2.4 \mathrm{GHz}$ transceiver, which is a digital wireless audio streaming chip. It uses infrared technology to stream MP3s, which are stored on a secure digital (SD) card within a handheld transmitter. A second nRF24Z1 serves as the receiving unit, which is housed in a casing located between the ear-pieces and the bell/diaphragm of a standardappearing stethoscope (Fig. 7). Sound signals pass through a digital-to-analog converter to a speaker and can be heard through the stethoscope's ear-pieces. The manufacturer provides a selection of sound files, including heart sounds, Korotkoff and vascular bruits, lung sounds, voice sounds, and bowel sounds. Up to 12 separate sound files can be transmitted by selecting combinations of 3 switch positions and 4 push-buttons on the transmitter. Breath sound files can be used so that single inspirations and expirations play when a (separate) button is actuated or as repeating inspiration-expiration loops. The major advantages of this device include high-fidelity audio (4 MB/s bandwidth) and the ability to rapidly select a range of sounds as the examiner auscultates various locations on the standardized patient or manikin. In addition, users can expand the inventory of sounds by adding their own MP3s to match the needs of more complex clinical simulations. ${ }^{36}$ Additional training of the standardized patient is necessary with the Ventriloscope. Breath sounds must be synchronized in

Table 3. Recording Stethoscopes

\begin{tabular}{|c|c|c|}
\hline Model and Company & Technology & Acoustics \\
\hline $\begin{array}{l}\text { Littman 4100ws } \\
3 \mathrm{M}\end{array}$ & $\begin{array}{l}\text { Three frequency modes allow listening from } 20 \text { to } \\
1,000 \mathrm{~Hz}\end{array}$ & $\begin{array}{l}\text { Up to } 18 \times \text { amplification. Reduces external room } \\
\text { noise by an average of } 75 \%(12 \mathrm{~dB})\end{array}$ \\
\hline $\begin{array}{l}\text { Echo+Plus DataLink } 59004 \\
\text { Trimline Medical Products }\end{array}$ & $\begin{array}{l}\text { One mini female microphone port (usually located near } \\
\text { CD ROM) }\end{array}$ & Digital mode $400 \%$ increase in amplification \\
\hline $\begin{array}{l}\text { ds32a } \\
\text { Thinklabs }\end{array}$ & $\begin{array}{l}\text { Record sounds with a Belkin Tunetalk, iPhone, iPod } \\
\text { Touch, iPod, or notebook computer }\end{array}$ & $50 \times$ amplification \\
\hline $\begin{array}{l}\text { E-Scope } 718-7700 \\
\text { Cardionics }\end{array}$ & $\begin{array}{l}\text { Connects to a desktop or handheld computer to display } \\
\text { phonocardiogram or phonopneumogram, with } \\
\text { StethView software }\end{array}$ & $\begin{array}{l}\text { Frequency switch: } 45-900 \mathrm{~Hz} \text { for heart sounds, } \\
50-2000 \mathrm{~Hz} \text { for lung sounds }\end{array}$ \\
\hline
\end{tabular}



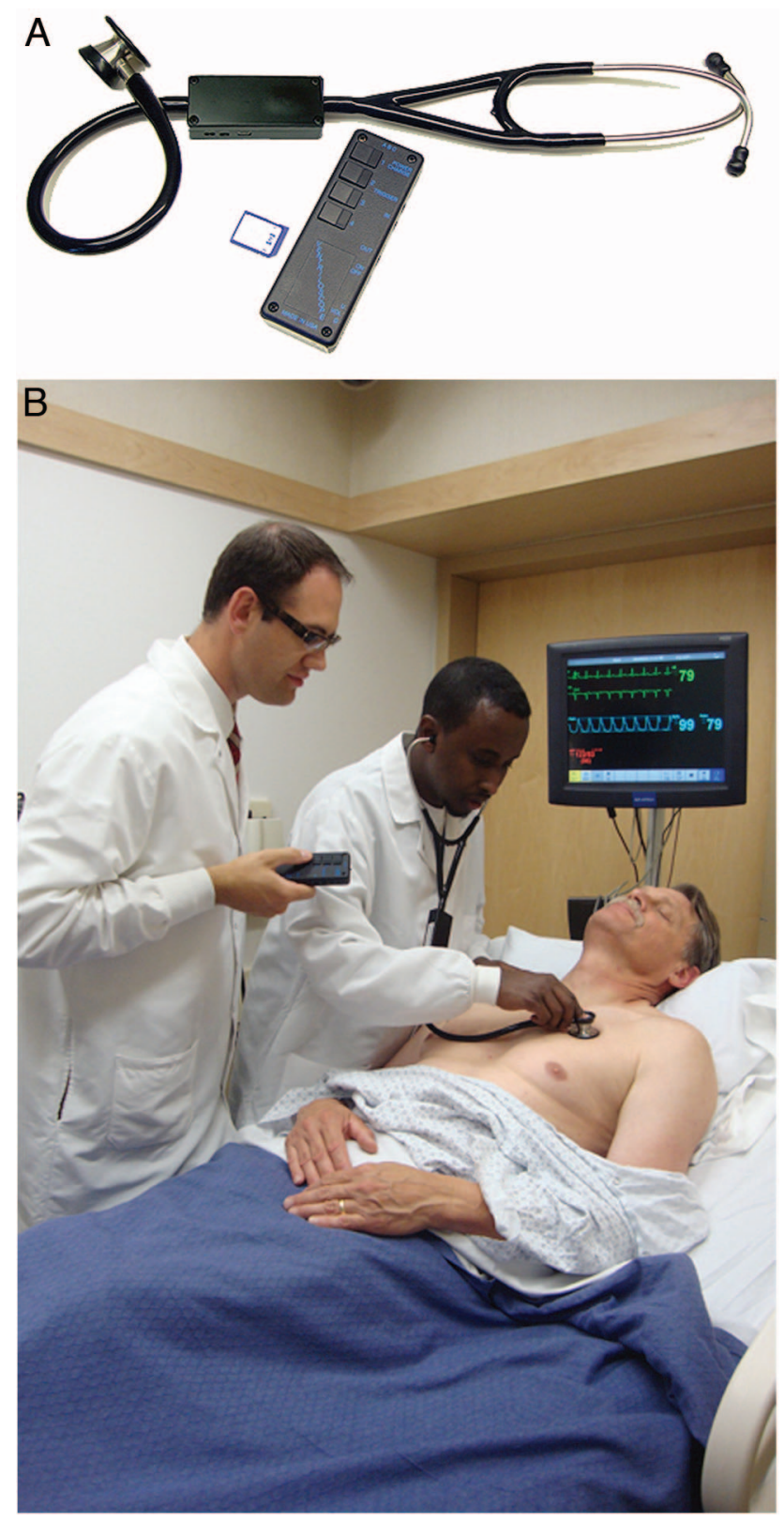

Fig. 7. A. Ventriloscope stethoscope and its transmitter and transceiver. B. Ventriloscope being used with a standardized patient. terms of rate and chest-wall movement, and are only activated when the bell or diaphragm contacts the chest. The individual operating the transmitter can also hear the sound, with an earphone connected to the transmitter. The standardized patient can operate the transmitter hidden under bedding or within garments. This poses a problem for a standardized patient when examiners auscultate the posterior thorax, as direct line of site is required for signaling. To solve this problem, simulation faculty can actuate controls outside the room, through one-way glass, or a confederate in the room can signal sounds surreptitiously. Learners or examinees must be prompted to understand that, although the Ventriloscope appears to be a relatively normal acoustic stethoscope, it will not respond like a standard stethoscope if they tap the bell or diaphragm.

Other digital playback devices can be adapted for simulation with a standard stethoscope or by replacing the ear-pieces with "ear-buds," which visually mimic an acoustic stethoscope (Table 4). The Sansa Shaker (SanDisk, Milpitas, California) was designed as an MP3 player for children (Fig. 8). It is easy for small hands to operate, and has a built-in speaker and 2 headphone ports. If the Sansa Shaker is shaken, it automatically shuffles the files that are pre-loaded on its SD card. When used for simulation, the examiner can either place the diaphragm or bell of their stethoscope on top of the Sansa Shaker's speaker or use a stethoscope-like ear-piece connected to one of the 1/8-inch headphone jacks. The disadvantage of this device is that the standardized patient or examiner must both manually position the device on the chest and press a button to play the sound file, which compromises the realism of the simulation. The user must twist a rotating collar on the base of the device to move through the files. Rotating the collar clockwise advances, whereas rotating counterclockwise repeats or moves backwards in the lineup of audio files. The advantage of this device is low cost and simplicity of technology. Commercial MP3 audio players adapted with stethoscope-like headphones can also be used. The major disadvantage is the loss of the appearance and function of a realistic stethoscope.

Table 4. Auscultation Sound Playback Devices and Stethoscopes

\begin{tabular}{llll}
\hline \hline \multicolumn{1}{c}{$\begin{array}{c}\text { Model and } \\
\text { Company }\end{array}$} & \multicolumn{1}{c}{ Technology } & \multicolumn{1}{c}{ Features } & Battery \\
\hline $\begin{array}{l}\text { Sansa Shaker } \\
\text { SanDisk }\end{array}$ & $\begin{array}{l}\text { 512 MB memory chip } \\
\text { Plays MP3 or PCM WAV }\end{array}$ & $\begin{array}{l}\text { 2 headphone jacks } \\
512 \text { MB memory chip } \\
\text { Uses 1 GB SD memory card }\end{array}$ & One AAA \\
Ventriloscope & Nordic nRF24Z1 2.4 GHz transceiver & 12 MP3 sound files & USB rechargeable batteries (8 h charge) \\
Lecat Ventriloscope & $4 \mathrm{MB} / \mathrm{s}$ bandwidth & $\begin{array}{l}\text { Headphone jacks on transmitter } \\
\text { Mock stethoscope appearance }\end{array}$ & \\
& & &
\end{tabular}



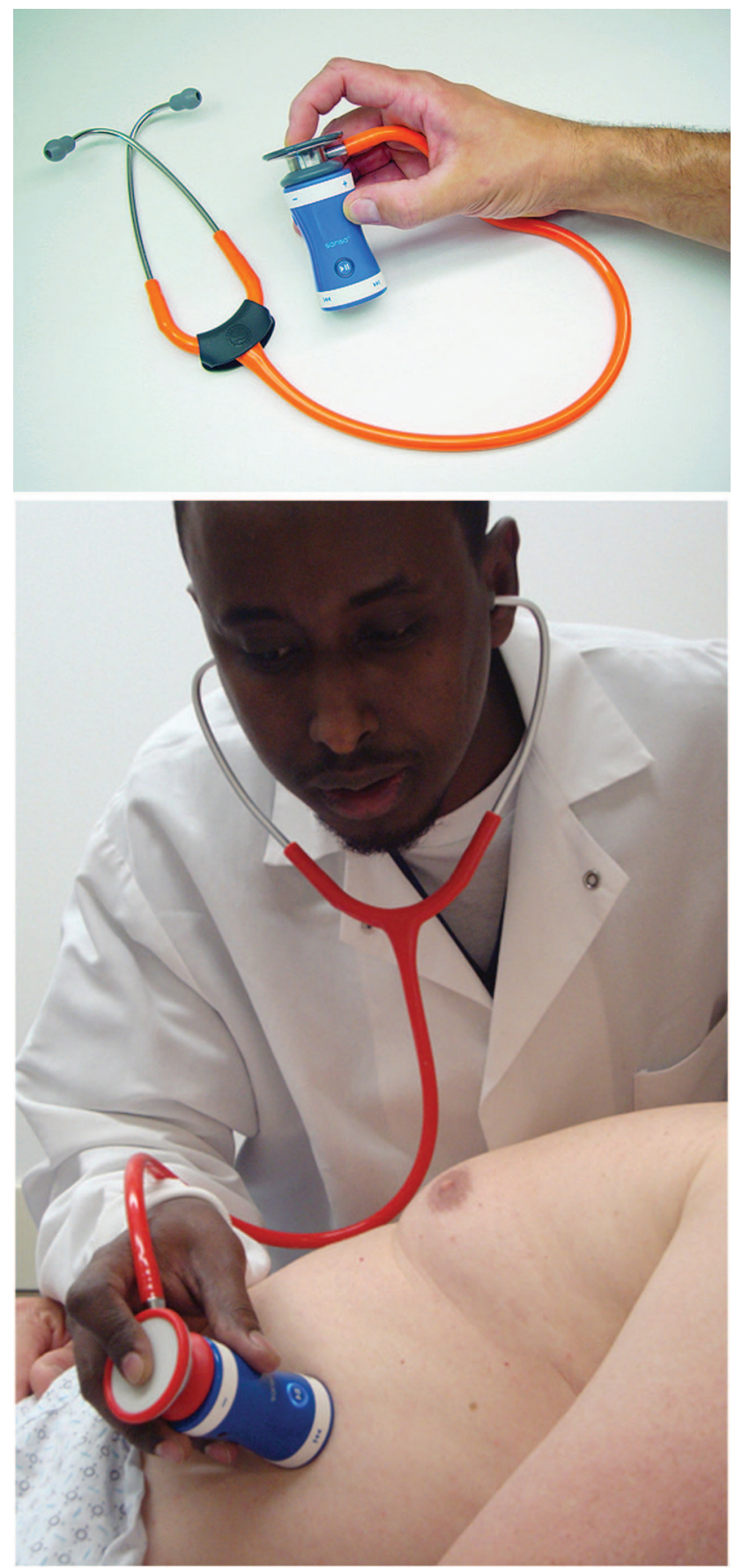

Fig. 8. Sansa Shaker used with standardized patient.

\section{Discussion}

Clinical competence in medical practice requires a wide range of skills, knowledge, and professional traits. The increasing complexity of medicine, advancing roles and responsibilities, and heightened demands for safety and quality place greater requirements on educators and managers. ${ }^{37,38}$ There has been a growing appreciation of the value of medical simulation for both education and assessment of cognitive, psychomotor, and interpersonal skill competencies. ${ }^{39,40}$ The increased importance of simulation is underscored as medical, nursing, and allied health education programs are challenged by compacted clinical hours, shorter patient stays, faculty shortages, and financial problems. ${ }^{41}$ The value of medical simulation is based on evidence of the validity of simulation when used as a formative education tool for students or as clinician transitions from novice to expert. However, the evidence hinges upon the quality, fairness, bias, and consequent actions from simulation-based assessment. ${ }^{42,43}$ As simulation is used as part of certification of licensure decisions, this certainly poses a high-stakes situation. ${ }^{44,45}$

Poor-quality reproduction of chest auscultation sounds during simulation training and testing can pose problems that may reduce the value for both learning and assessment. At our simulation center, learners have commented that either inability to hear or distortion of lung sounds caused confusion as they integrated interpretation of physical exam findings in manikin simulations. In some instances the manikin's internal mechanical noises were interpreted as equal and bilateral breath sounds when a pneumothorax sound was induced or endobronchial intubation was present. In our experience, the manufacturersupplied crackles sound transmitted in a full-body manikin is the most challenging adventitious sound for learners to hear. The detection of crackles appears to challenge human auditory perception, even under real and well controlled circumstances. ${ }^{46}$

Medical simulation scenarios with standardized patients have become a common evaluation method since being adopted as objective structured clinical examinations for medical schools in the mid-1970s. ${ }^{47}$ Clinical simulations with standardized patients have also become accepted as a teaching tool. ${ }^{48}$ Education theory supports simulation to both teach and evaluate clinical competence in patient-centered clinical skills such as interpersonal communication, history taking, and physical examination. Since the late 1960s there has been growing acceptance of simulation scenarios to develop the integration of complex information, clinical reasoning, and problem-solving skills. ${ }^{49,50}$ Real patients, unlike standardized patients, often have restrictions on their access and availability, so providing a uniform experience to multiple learners is often not feasible. A major disadvantage of standardized patients is the investment in their training time. ${ }^{50}$ Despite the numerous studies on simulation, there have been very few high-quality studies with outcome measurement of value for education or assessment with standardized patients. ${ }^{51}$ An important problem with standardized patients has been that they could not demonstrate pathologic pulmonary or cardiac auscultation findings, but creative application of digital 


\section{Technology for Enhancing Chest Auscultation in Clinical Simulation}

audio technology now allows us to simulate those sounds in healthy standardized patients. ${ }^{10,36}$

\section{Summary}

The clinical value of auscultation as part of the traditional physical exam has been criticized in the medical literature because of auscultation's subjectivity, imprecision, high observer variability, and the inability to quantify cardiovascular or pulmonary problems. ${ }^{13,52,53}$ Most medical instruments that were invented in the 1800 s currently reside in museums. ${ }^{54}$ However, there are times when auscultation with a basic acoustic stethoscope may not need to be updated. When combined with focused physical exam and history, chest auscultation can guide immediate and potentially life-saving interventions in patients with asthma exacerbation, pneumothorax, massive pleural effusion, misplaced endotracheal tube, large-airway obstruction, stridor and/or crackles in dependent lung zones from heart failure. 55

Fortunately, many limitations of the classic mechanical acoustic tool can be easily compensated by modern digital/ computer technology, including the ability to store and play audio and graphic representations of heart, vascular, and pulmonary sounds. ${ }^{56,57}$ Such technology offers promise in the classroom, learning lab, and at computer terminals, to provide initial instruction with audio and video files. Medical simulation scenarios with standardized patients or manikins allow learners to integrate acoustic data with related clinical information. Today, educators and managers can enhance the value of a learning experience with technology of digital sound files and high-quality debriefing. ${ }^{58}$ Since there is considerable variation in chest sounds among patients, learning opportunities can continue beyond the simulation center with the help of experienced mentors in live patient interactions.

\section{ACKNOWLEDGMENTS}

We thank Thomas Belda RRT and Cheryl Paulson RRT, Multidisciplinary Simulation Center, Mayo Clinic, Rochester, Minnesota, for technical assistance.

\section{REFERENCES}

1. Issenberg SB, McGaghie WC, Hart IR, Mayer JW, Felner JM, Petrusa ER, et al. Simulation technology for health care professional skills training and assessment. JAMA 1999;282(9):861-866.

2. Bradley P. The history of simulation in medical education and possible future directions. Med Educ 2006;40(3):254-262.

3. Seropian MA, Brown K, Gavilanes JS, Driggers B. Simulation: not just a manikin. J Nurs Ed 2004;43(4):164-169.

4. Gordon JA, Brown DF, Armstron EG. Can a simulated critical care encounter accelerate basic science learning among preclinical medical students? A pilot study. Simul Healthc 2006;(1):13-17.
5. Seropian M, Dillman D, Lasater K, Gavilanes J. Mannequin-based simulation to reinforce pharmacology concepts. Simul Healthc 2007; 2(4):218-223.

6. Issenberg SB, Gordon MS, Gordon DL, Safford RE, Hart IR. Simulation and new learning technologies. Med Teach 2001;23(1):1623.

7. Kohn LT, Corrigan JM, Donaldson MS, editors. To err is human: building a safer health system. Washington, DC: National Academy Press; 2000.

8. Gaba DM. The future vision of simulation in health care. Qual Saf Health Care 2004;13(Suppl 1):i2-i10.

9. Issenberg SB, McGagie WC, Petrusa ER, Lee Gordon D, Scalese RJ. Features and uses of high-fidelity medical simulations that lead to effective learning: a BEME systematic review. Med Teach 2005; 27(1):10-28.

10. Sun B, McKenzie FD, Garcia HM, Hubbard TW, Ullian JA, Gliva GA. Medical student evaluation using augmented standardized patients: new development and results. Stud Health Technol Inform 2007; 125:454-456.

11. Pasterkamp H, Kraman SS, Wodicka GR. Respiratory sounds: advances beyond the stethoscope. Am J Respir Crit Care Med 1997; 156(3 Pt 1):974-987.

12. Lichtenstein D, Goldstein I, Mourgeon E, Cluzel P, Grenier P, Rouby JJ. Comparative diagnostic performances of auscultation, chest radiography, and lung ultrasonography in acute respiratory distress syndrome. Anesthesiology 2004;100(1):9-15.

13. Hubmayr RD. The times are a-changin': should we hang up the stethoscope? Anesthesiology 2004;100(1):1-2.

14. Ceresa CC, Johnston ID. Auscultation in the diagnosis of respiratory disease in the 21st century. Postgrad Med J 2008;84(994):393-394.

15. Druger G. The chest: its signs and sounds. Los Angeles: Humetrics; 1973.

16. Wilkins RL, Hodgkin JE, Lopez B. Lung sounds: a practical guide. St Louis: Mosby; 1988.

17. Mangione S, Nieman LZ, Gracely EJ. Comparison of computerbased learning and seminary teaching of lung auscultation to firstyear medical students. Acad Med 1992;67(10 Suppl):S63-S65.

18. Mangione S, O'Brien MK, Peitzman SJ. Small-group teaching of chest auscultation to third-year medical students. Acad Med 1997; 72(10 Suppl 1):S121-S123.

19. Issenberg SB, Petrusa ER, McGaghie WC, et al. Heavy breathingadvances in lung and cardiology education. Acad Med 1999; 74(Suppl):S93-S95.

20. Karnath BM, Das Carlo M, Holden MD. A comparison of faculty-led small group learning in combination with computer-based instruction versus computer-based instruction alone on identifying simulated pulmonary sounds. Teach Learn Med 2004;16(1):23-27.

21. Issenberg SB. Gordon MS. Greber AA. Bedside cardiology skills training for the osteopathic internist using simulation technology. J Am Osteopath Assoc 2003;103(12):603-607.

22. Ewy GA, Felner JM, Juul D, Mayer JW, Sajid AW, Waugh RA. Test of a cardiology patient simulator with students in fourth-year electives. J Med Educ 1987;62(9):738-743.

23. Woolliscroft JO, Calhoun JG, Tenhaken JD, Judge RD. Harvey: the impact of a cardiovascular teaching simulator on student skill acquisition. Med Teach 1987;9(1):53-57.

24. Takashina T, Shimizu M, Katayama H. A new cardiology patient simulator. Cardiology 1997;88(5):408-413.

25. Yoshii C, Anzai T, Yatera K, Kawajiri T, Nakashima Y, Kido M. A new medical education using a lung sound auscultation simulator called "Mr Lung". J UOEH 2002;24(3):249-255.

26. Herrmann EK. Connecticut nursing history vignettes: remembering Mrs. Chase. Conn Nurs News 2008;Mar-May. 


\section{Technology for Enhancing Chest Auscultation in Clinical Simulation}

27. Ad Hoc Committee on Cardiopulmonary Resuscitation of the Division of Medical Sciences; National Academy of Sciences National Research Council. Cardiopulmonary resuscitation. JAMA 1966; 198(4):372-379

28. Cooper JB, Taqueti VR. A brief history of the development of mannequin simulators for clinical education and training. Qual Saf Health Care 2004;13(Suppl 1):11-18. Erratum in: Qual Saf Health Care 2005;14(1):72.

29. McKusick VA, Jenkins JT, Webb GN. The acoustic basis of the chest examination; studies by means of sound spectrography. Am Rev Tuberc 1955;72(1):12-34

30. Murphy RL Jr, Holford SK, Knowler WC. Visual lung sound characterization by time expanded wave-form analysis. N Engl J Med 1977;296(17):968-971.

31. Wodicka GR, Stevens KN, Golub HL, Shannon DC. Spectral characteristics of sound transmission in the human respiratory system. IEEE Trans Biomed Eng 1990;37(12):1130-1135.

32. Sovijarvi AH, Vanderschoot J, Earis JE. Computerized respiratory sound analysis (CORSA): recommended standards for terms and techniques. Eur Respir Rev 2000;10:585-649.

33. Kompis M. Pasterkamp H. Wodicka GR. Acoustic imaging of the human chest. Chest 2001;120(4):1309-1321.

34. Murphy RL, Vyshedskiy A, Power-Charnitsky VA, Bana DS, Marinelli PM, Wong-Tse A, Paciej R. Automated lung sound analysis in patients with pneumonia, Respir Care 2004;49(12):1490-1497.

35. Fiz JA, Jane R, Homs A, Izquierdo J, Garcia MA, Morera J. Detection of wheezing during maximal forced exhalation in patients with obstructed airways. Chest 2002;122(1):186-191.

36. Castilano A, Haller N, Goliath C, Lecat P. The Ventriloscope: 'am I hearing things?' Med Teach 2009;31(3):e97-e101.

37. Kacmarek RM, Durbin CG Jr, Barnes TA, Kageler WV, Walton JR, O'Neil EH. Creating a vision for respiratory care in 2015 and beyond. Respir Care 2009;53(3):375-389.

38. Barnes TA, Gale DD, Kacmarek RM, Kageler WV. Competencies needed by graduate respiratory therapists in 2015 and beyond. Respir Care 2010;55(5):601-616.

39. McGuire $\mathrm{CH}$, Babbott D. Simulation technique in the measurement of problem-solving skills. J Ed Meas 1967;4(1):1-10.

40. Epstein RM. Assessment in medical education. N Engl J Med 2007; 356(4):387-396.

41. Albanese M, Mejicano G, Gruppen L. Perspective: competencybased medical education: a defense against the four horsemen of the medical education apocalypse. Acad Med 2008;83(12):1132-1139.

42. Andreatta PB, Gruppen LD. Conceptualising and classifying validity for simulation. Med Ed 2009;43(11):1028-1035.
43. Decker S, Sportsman S, Puetz L, Billings L. The evolution of simulation and its contribution to competency. J Contin Educ Nurs 2008;39(2):74-80.

44. Boulet JR, Smee SM, Dillon GF, Gimpel JR. The use of standardized patient assessments for certification and licensure decisions. Simul Healthc 2009;4(1):35-42.

45. Dillen GF, Boulet JR, Hawkins RE, Swanson DB. Simulations in the United States Medical Licensing Examination (USMLE). Qual Saf Health Care 2004;213(Suppl 1):i41-i45.

46. Kiyokawa H, Greenberg M, Shirota K, Pasterkamp H. Auditory detection of simulated crackles in breath sounds. Chest 2001;119(6): 1886-1892.

47. Harden RM, Stevenson M, Downie WW, Wilson GM. Assessment of clinical competence using objective structured examination. $\mathrm{Br}$ Med J 1975;1(5955):447-451.

48. Brazeau C, Boyd L, Crosson J. Changing an existing OSCE to a teaching tool: the making of a teaching OSCE. Acad Med 2002; 77(9):932.

49. Beker KL, Rose LE, Berg JB, Park H Shatzer JH. The teaching effectiveness of standardized patients. J Nurs Ed 2006;45(4)103111

50. Bokken L, Rethans J, Scherpbier A, van der Vleuten CP. Strengths and weaknesses of simulated and real patients in the teaching of skills to medical students: a review. Simul Healthc 2008;3(3):161169

51. Howley L, Szauter K, Perkowski L, Clifton M, McNaughton. Quality of standardized patent research reports in the medical education literature: review and recommendations. Med Ed 2008;42(4):350358.

52. Jauhar S. The demise of the physical exam. N Engl J Med 2006; 354(6):548-551.

53. Markel H. The stethoscope and the art of listening. N Engl J Med 2006;354(6):551-553.

54. Laennec RT. De l'auscultation mediate, volume 2. Paris: Brosson \& Chade; 1819.

55. Murphy R. In defense of the stethoscope. Respir Care 2008;53(3): 355-369.

56. Conn RD, O'Keefe JH. Cardiac physical diagnosis in the digital age: an important but increasingly neglected skill (from stethoscopes to microchips). Am J Cardiol 2009;104(4):590-595.

57. Tavel ME. Cardiac auscultation: a glorious past-and does it have a future! Circulation 2006;113(9)1255-1259.

58. Rudolph JW, Simon R, Dufresne RL, Raemer DB. There's no such thing as "nonjudgmental" debriefing: a theory and method for debriefing with good judgment. Simul Healthc 2006;1(1):49-55. 